\title{
International Journal of Computer Science, Engineering and Information Technology (IJCSEIT)
}

ISSN: 2231 - 3117 [Online] ; 2231 - 3605 [Print]
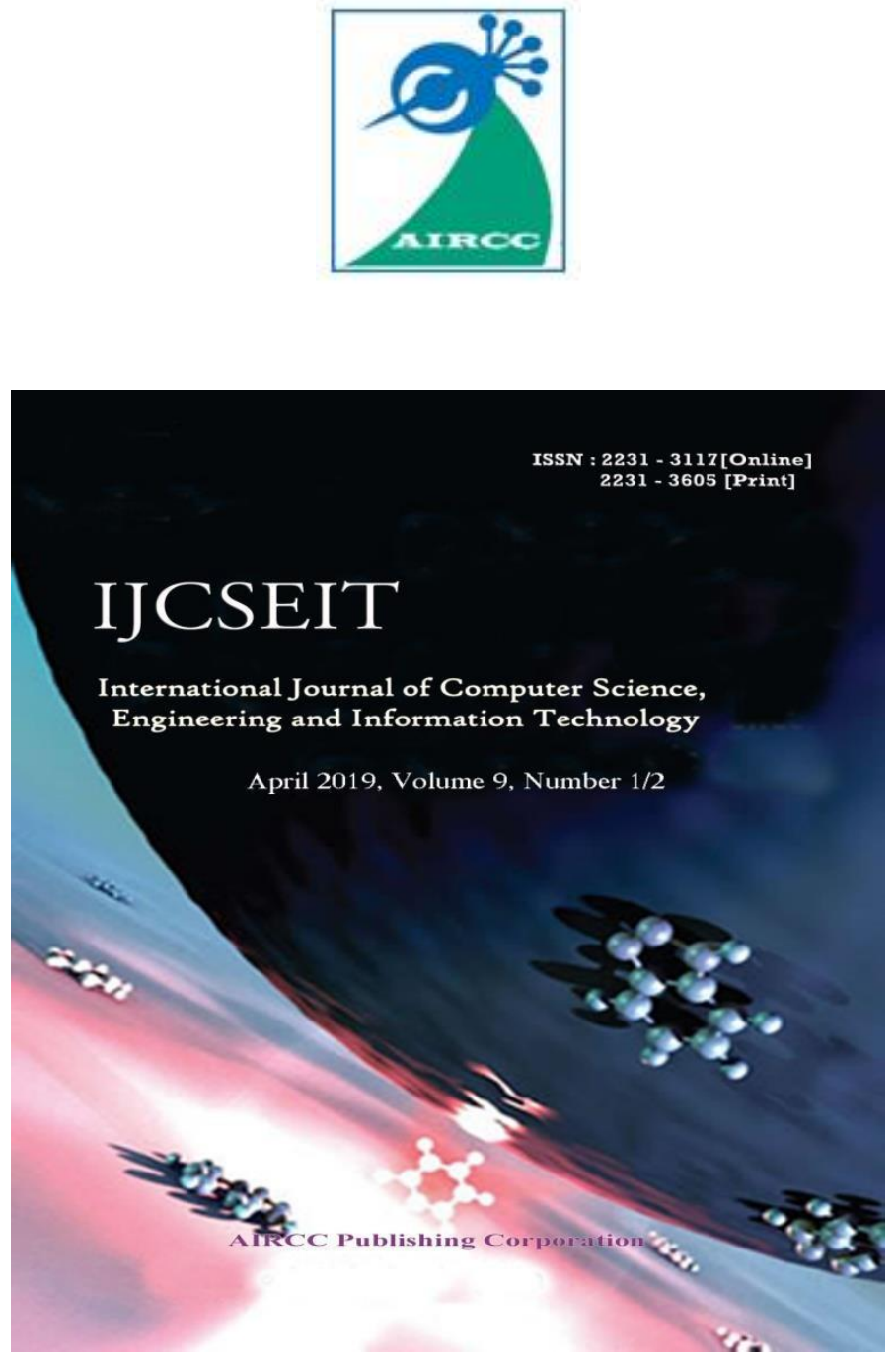

https://airccse.org/journal/ijcseit/ijcseit.html 


\section{SCOPE OF THE JOURNAL}

International Journal of Computer Science, Engineering and Information Technology (IJCSEIT) will provide an excellent international forum for sharing knowledge and results in theory, methodology and applications of Computer Science, Engineering and Information Technology. The Journal looks for significant contributions to all major fields of the Computer Science and Information Technology in theoretical and practical aspects. The aim of the Journal is to provide a platform to the researchers and practitioners from both academia as well as industry to meet and share cutting-edge development in the field.

All submissions must describe original research, not published or currently under review for another conference or journal.

\section{Topics of interest include but are not limited to, the following}

- Algorithms and Bioinformatics

- Computer Architecture and Real time Systems

- Database and Data Mining

- Dependable, reliable and autonomic computing

- Distributed and parallel systems \& algorithms

- DSP/Image Processing/Pattern Recognition/Multimedia

- Embedded system and software

- Game and software engineering

- Geographical Information Systems/ Global Navigation Satellite Systems (GIS/GNSS)

- Grid and scalable computing

- Intelligent Information \& Database Systems

- IT policy and business management

- Mobile and ubiquitous

- computingModeling and Simulation Multimedia systems and services

\section{https://airccse.org/journal/ijeseit/ijeseit.html}


- Networking and communications

- Performance Evaluation

- Programming Languages

- Security and Information Assurance

- $\quad$ Soft Computing (AI, Neural Networks, Fuzzy Systems, etc.)

- Software Engineering

- Web and internet computing

- Theoretical computer science

- Natural Language Processing

- Operating Systems

- Compiler Design

- Computer Education

- Information Technology Management

- Recent Trends in Information technology

- e-Learning, e-Business, Enterprise Information Systems and e-Government 


\section{Members of the Editorial Board}

\section{Editor-in-Chief :}

Murugan Dhanuskodi, Manonmaniam Sundaranar University, India

\section{Editorial board Members :}

Abdelouahed Sabri, Dhar El mahraz FES, Morocco

Abolfazl Zargari Khuzani, University of Oklahoma, USA

Abdul kadir Ozcan, Karatay University, Turkey

Ahmed Y. Nada AQU, Al-Quds University, Palestine

Aman Chadha, University of Wisconsin-Madison, USA

Amando P. Singun, Higher College of Technology, Oman

Anamika Ahirwar, Rajiv Gandhi Technical University, India

Anand Nayyar, Duy Tan University, Vietnam

Antelin Vijila, Manonmaniam Sundaranar University, India

Arvinth Kumar, M.S.University, India

Balasubramaniam,Manonmaniam Sundaranar University, India

Chin-Chih Chang, Chung Hua University, Taiwan

Christo Ananth, College of Engineering, Salmabad, Kingdom of Bahrain

Deepak Garg, Thapar University, India

Dinesh Kumar A, Dhanalakshmi Srinivasan Engineering College, India

Durjoy Majumder, West Bengal State University, India

Deepali Gupta, Maharishi Markandeshwar University, India

Elboukhari Mohamed,University Mohamed First, Tunisia

Farooq Aftab, University of Science and Technology Beijing, China

Faudziah Ahmad, Universiti Utara Malaysia, Malaysia

Gaurang Panchal, IIT Kharagpur, India 
Govindraj B. Chittapur, Basaveswar Engineering College,India

Guna Sekaran, Pavendar Bharathidasan College of Engineering and Technology, India

Harsh Pratap Singh, Sri Satya Sai University of Technology \& Medical Sciences, India

Hao-En Chueh, Yuanpei University, Taiwan

Hedayat Omidvar, National Iranian Gas Company, Iran

Isa Maleki, Islamic Azad University, Iran

J.Arunadevi, Thiagarajar college,Madurai, India

Jafar A. Alzubi, Al-Balqa Applied University, Jordan

Jansirani, Manonmaniam Sundaranar University, India

Jehad Al Dallal, Kuwait University, Kuwait

Jeremy (Zheng) Li, University of Bridgeport, USA

Kannan, Anna University, India

Kannan A, K.L.N.College of Engineering, India

Keivan Borna, Kharazmi University, Iran

Krishna Prasad P.E.S.N, Prasad V. Potluri Siddhartha Institute of Technology, India

Krishnan,Manonmaniam Sundaranar University, India

L.Ganesan, Alagappa University, India

Malleswaran M, Anna University, India

Mansaf Alam, Jamia Millia Islamia, India

Md. Sadek Ali, Islamic University,Bangladesh

Md. Shariful Islam,Islamic University,Bangladesh

Murugeswari, M.S.University, India

Muthulakshmi, M.S.University, India

Naren, SASTRA University, India

Natarajan Meghanathan, Jackson State University, United States

Neerajkumar, Madha Vaisnavi Devi University, India

https://airccse.org/journal/ijcseit/ijcseit.html 
Prasenjit Chanak, Indian Institute of Engineering Science and Technology, India

PushpinderSingh Patheja, Bansal Institute of Science and Technology, India

Rahul Saha, Lovely Professional University, India

Rajalakshmi, Manonmaniam Sundaranar University, India

Rajesh, Manonmaniam Sundaranar University, India

Rajesh Bawa, Punjabi University, India

Ramakrishnan S, Mahalingam College of Engineering \& Technology, India

Ritu Sharma, Himachal Pradesh University, India

Ruchi Doshi, BlueCrest University College, West Africa

S.Arumugam,Nandha Engg college, India

Sadasivam, Manonmaniam Sundaranar University, India

Saeid Pashazadeh,University of Tabriz, Iran

Sandhya M, B.S.Abdur Rahman University, India

Sandhya Tarar, Gautam Buddha University, India

Satish Mittal, Punjabi University, India

Seemabawa, Thapar University, India

Shaikh Ullah, University of Rajshahi, Bangladesh

Singh M.P, National Institute of Technology Patna, India

Sornam M, University of Madras, India

Subha, M.S.University, India

Sundaresan,Manonmaniam Sundaranar University, India

Suresh Sankaranarayanan, Institut Teknologi Brunei, Brunei

Suruliandi, Manonmaniam Sundaranar University, India

Syed Ziaur Rahman, Ministry of Higher Education, Sultanate of Oman

Thamaraiselvi, Madras Institute of Technology, India

Twaibu Semwogerere, Busitema University, Uganda

Thambidurai, Pondicherry University, India

Ujjwal Agarwal, Salalah College of Technology, Oman

Umesh Kumar Lilhore, SAGE University, India

Umesh Lilhore, NRI Institute of Information Science and Technology Bhopal, India

https://airccse.org/journal/ijeseit/ijcseit.html 
Usama Ibraheem, Al-Nahrin University, Iraq

Vijay Mankar, Govt. Polytechnic, India

Vuda Sreenivasa Rao, Bahir Dar University, Ethiopia

Yixiong XU, Shanhai Aerospace Control Technology Institute, China

\section{Reviewer}

Hamid Ali Abed Al-asadi, Basra University, IraqHamid Ali Abed

Shukla K.B, SAL-ITER, India

Niranjanamurthy M, MS Ramaiah Institute of Technology,India

Hamid Bagheri, Iowa State University, USA 


\section{Paper Submission \& Manuscript preparation Guide}

\section{Paper Submission}

Authors are invited to Submit papers for this journal through Email: ijcseit@aircconline.com or through Submission System. Submissions must be original and should not have been published previously or be under consideration for publication while being evaluated for this Journal. For paper format download the template in this page

\section{$\underline{\text { Manuscript Template }}$}

\section{Review process}

Submissions are accepted for review with the understanding that the same work has been neither submitted to, nor published in, another publication. Simultaneous submission to other publications will result in immediate rejection of the paper. Papers are not within the journal scope will be rejected immediately after the pre review process.

All manuscripts will be subject to a well established, fair, unbiased peer review and refereeing procedure, and are considered on the basis of their significance, novelty and usefulness to the Journals readership. The reviewing structure will always ensure the anonymity of the referees \& it will be reviewed by 3 experts in the field. The review output will be one of the following decisions:

\section{Accept}

2. Accept with minor changes

3. weak Accept with major changes

4. Reject

The review process may take approximately two three months to be completed. The Editor reserves the right to reject a paper if it does not meet the aims and scope of the journal, it is not revised well.

\section{Special Issue Proposal}

IJCSEIT invite proposals for special issues on topics that fall within the scope of this journal. Please email your proposal to secretary@airccse.org.

\section{Copy right form}

After submitting final manuscript, you can get copy right form from AIRCC secretary

\section{Contact Us}

Here's where you can reach us : ijcseitjournal@yahoo.com or ịcseit@aircconline.com 


\section{Indexing}

Abstracting \& Indexing Services:

The Articles of IJCSEIT are Indexed / Abstracted in the Following Index Services

Google

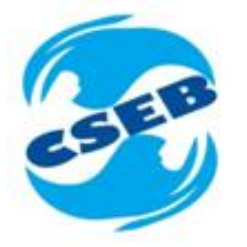

Scribd.

O) Unacheswers

getCITED

pubget

ProQuest CiteSeer ${ }_{\text {beta }}^{*}$

docstac

(a) Scilit

5) WorldCat

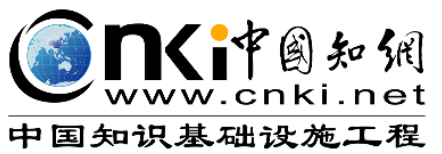

(10)AJD

Bibliographic Information

ISSN : $2231-3605$

e-ISSN : 2231 - 3117

doi : 10.5121/ijcseit 


\section{Google Scholar Indexing}

H -Index - 24, Citations 2371, i10-Index 49

more details

https://scholar.google.com/citations?user=W-3KjKEAAAAJ\&hl=en

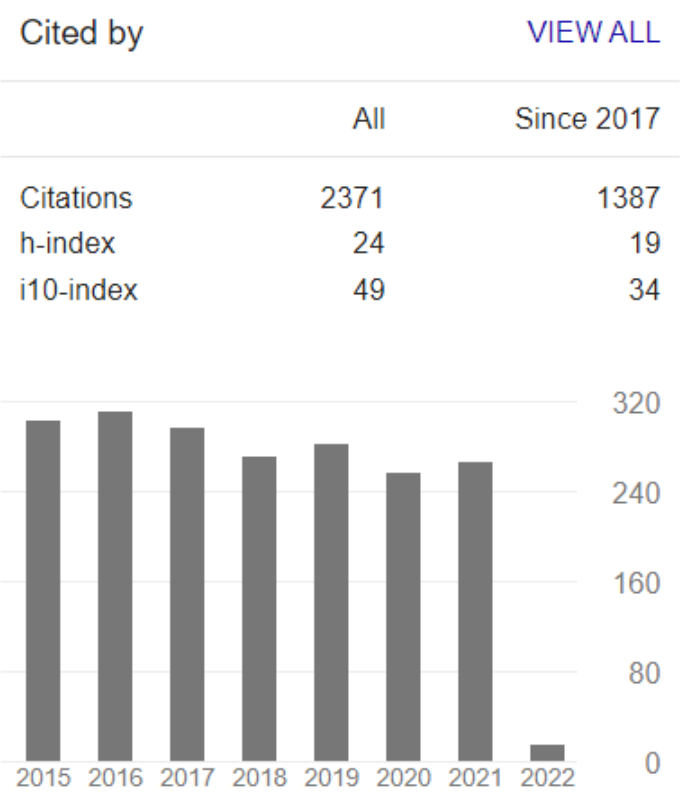

https://airccse.org/journal/ijcseit/ijcseit.html 